courts in 1991, and asbestos-containing products are therefore allowed currently in US markets.

Proposal for eliminating ARDs A complete ban on all manufacture and use of asbestos worldwide is the only strategy to end the global pandemic of ARDs. The possibility of securing an asbestos ban in the USA was rekindled in 2016 with passage of new chemical safety legislation. Asbestos is listed under this law as a priority chemical. Responsibility for enforcement rests with the Trump Administration.

\section{PRACTICE OF OCCUPATIONAL HEALTH SERVICES (IMPLEMENTATION OF SEOUL STATEMENT ON THE DEVELOPMENT OF OCCUPATIONAL HEALTH SERVICES FOR ALL)}

\begin{abstract}
${ }^{1}$ Seong-Kyu Kang*, ${ }^{2}$ Jorma Rantanen*, ${ }^{3}$ Jong-Kyu Kwon*, ${ }^{4}$ Stefano Mattioli*. 'Gachon University Gil Medical Centre, Incheon, Republic of Korea; ${ }^{2}$ Past President of ICOH, Helsinki, Finland; ${ }^{3}$ Korea Occupational Safety and Health Agency (KOSHA), UIsan, Republic of Korea; ${ }^{4}$ University of Bologna, Bologna, Italy
\end{abstract}

\subsection{6/oemed-2018-ICOHabstracts.636}

Aim of special session The Seoul Statement has announced during ICOH Congress2015, which contains the recommendation on development of occupational health services for all. In this session, representative of each continent or region will speak about the progress of occupational health services in their continents or regions.

Presenters: ${ }^{1}$ Doo Yong Park, ${ }^{2}$ Simon Bulterys, ${ }^{3}$ Jarmo Heikkinen, ${ }^{4}$ Carmen Busneag, ${ }^{5}$ Eun A Kim, ${ }^{6}$ Toru Yoshigawa, ${ }^{7} \mathrm{R}$ Rajesh, ${ }^{8}$ Rosylane Rocha, ${ }^{9}$ Cheikh Cisse, ${ }^{10}$ Jani Ruotsalainen

${ }^{1}$ Korea Occupational Safety and Health Research Agency (KOSHA), Ulsan, Republic of Korea

${ }^{2}$ IDEWE External Service for Prevention and Protection at Work, Leuven, Belgium

${ }^{3}$ University of Eastern Finland, Kuopio, Finland,

${ }^{4}$ National Romania Television, Bucharest, Romania

${ }^{5}$ Occupational Safety and Health Research Institute, Korea Occupational Safety and Health Agency, Ulsan, Rep. of Korea

${ }^{6}$ National Institute of Occupational Safety and Health, Kawasaki, Japan

${ }^{7}$ Reliance Industries Limited, Mumbai, India

${ }^{8}$ Hospital Regional da Asa Norte (HRAN), Brasilia, Brazil

${ }^{9}$ Integral Office of Occupational Health, Safety and Environment, Dakar, Senegal

${ }^{10}$ Finnish Institute of Occupational Health, Kuopio, Finland

\section{9a OCCUPATIONAL HEALTH SERVICES IN BELGIUM AND OHS STRATEGY 2020 IN THE EU}

SP Bulterys. IDEWE External Service for Prevention and Protection at Work, Leuven, Belgium

\subsection{6/oemed-2018-ICOHabstracts.637}

In Belgium the support to the internal service in well-being at work and occupational medicine is typically delivered by multidisciplinary external services. Due to the extent of services delivered, the number of services decreased and most of the Belgian working population is served by a small number of large services that have 400-800 own personnel. Half of the personnel is delivering occupational health services, the other half is advising and supporting in occupational safety, psychosocial factors at work, ergonomics and industrial hygiene.
Some recent changes in activity and newer tendencies in the field of occupational medicine and well-being at work in general will be discussed.

The EU has developed an OHS strategy 2020: Healthy Workplaces for all ages, promoting a sustainable working life. This strategy was translated in The Healthy Workplaces Campaign 2016-2017. The Occupational Medicine Section of UEMS (European Union of Medical Specialists) was a partner in this strategy and campaign. The main issues and key objectives of this campaign will be shown. Important themes were prevention throughout working life, the workability concept, a diversity-sensitive risk analysis, workplace adaptation and disability prevention, rehabilitation and return to work. There was also attention to newer issues like cooperation between Human Resources and OSH management and workplace health promotion. Besides of improving the health and well being of all employees, this shall also improve productivity and cost-effectiveness at organisational level.

\section{$1719 \mathrm{~b}$ EVALUATION OF EDUCATION OF SPECIALIST OCCUPATIONAL HEALTH PHYSICIANS IN THE PERIOD 2009-2013 IN FINLAND}

J Heikkinen, K Räsänen. Faculty of Health Sciences, Institute of Public Health and Clinical Nutrition, University of Eastern Finland, Kuopio, Finland

\subsection{6/oemed-2018-ICOHabstracts.638}

A nationwide external quality evaluation was carried to identify strengths, good practices and areas in need of development. The enhancement-led evaluation process included a selfevaluation report by the universities; evaluation interviews and visits by the evaluators; an evaluation report; a feed-back seminar. The evaluation focused on the management and planning of education, the learning philosophy and defining evaluating outcomes; the education resources and pedagogical training; the constructive alignment of education; the continuous development of education.

Key strengths included good cooperation between units, pedagogical training of the trainers, investment in web-based learning and the repetitive evaluations. Areas needing development included clarifying of the learning philosophy, broadening the learning outcomes to cover competences, achieving higher visibility, diversifying practices for learning assessment and feedback. Also, evaluators suggested more reflection practices to support professional growth; advancing pedagogical training of trainers; increasing the throughput of students and promoting the specialty to medical students. Genuinely interactive virtual learning was emphasised. Scientific research on and international approach of developing education were encouraged.

After the report the learning philosophy was clarified in the new curriculum, reflection was included in the logbook and a project started to develop evaluation of the learning outcomes as competencies and EPAs. A pedagogical webbased course and a guidebook for trainers were published. The universities have worked also on the external challenges: the changes in working life, the upcoming national reform of specialist medical education and the continuity of funding. High quality in medical education is essential. An external evaluation may substantially help to meet this challenge. 